\title{
Mucosal subepithelial binding sites for the bacterial chemotactic peptide, formyl-methionyl-leucyl-phenylalanine (FMLP)
}

\author{
P Anton, J O’Connell, D O’Connell, L Whitaker, G C O’Sullivan, J K Collins, F Shanahan
}

\begin{abstract}
Background-The bacterial chemotactic peptide $\quad N$-formyl-methionine-leucinephenylalanine (FMLP) is produced by enteric flora and is one of the factors implicated in contributing to inflammatory bowel disease. Expression of receptors for FMLP on human phagocytes (polymorphs and monocytes) is well established, but there is conflicting evidence regarding the potential expression of FMLP receptors on other cells within the mucosa, particularly the epithelial cells.

Aims-To map FMLP receptors within intestinal mucosa using several different experimental approaches.
\end{abstract}

Methods and results-Radioligand binding assays with ${ }^{3}$ H-FMLP revealed no specific binding to primary cultured colonic enterocytes or to the cell line HT29, whereas neutrophils, as expected, exhibited specific binding with a Kd of $19 \mathrm{nM}$ and approximately $2 \times 10^{4}$ receptors per cell. FITC labelled FMLP exhibited specific, displaceable binding on flow cytometry to neutrophils and monocytes but not to 10 gastrointestinal epithelial cell lines. Isolated lamina propria lymphocytes and peripheral blood lymphocytes exhibited no binding. To confirm the absence of receptors on epithelia, reverse transcription polymerase chain reaction for $\mathrm{mRNA}$ for the classic FMLP receptor was performed. While the presence of message was detected in activated peripheral blood phagocytes, it was not detected in epithelial cell lines. To exclude the possibility of FMLP binding to other receptors such as tachykinin receptors on epithelia, FITC labelled FMLP binding in tissue sections confirmed that the binding is subepithelial-that is, in the lamina propria.

Conclusion-Receptors for FMLP are subepithelial and map to the lamina propria of the gastrointestinal mucosa. (Gut 1998;42:374-379)

Keywords: formyl-methionyl-leucyl-phenylalanine; FMLP; mucosa; chemotaxis; gastrointestinal tract

Proinflammatory peptides are produced by aerobic and anaerobic bacteria including those within the enteric lumen. ${ }^{1}$ The $\mathrm{NH}_{2}$ terminal formyl peptides have potent chemotactic activity with formyl-methionyl-leucylphenylalanine (FMLP) being the major peptide chemotactic factor produced by Es- cherichia coli. ${ }^{2}$ It is produced by intestinal bacteria in vitro, ${ }^{3}$ and is present in micromolar concentrations in faecal dialysis fluid ex vivo. ${ }^{4}$ Colonic instillation of FMLP has been used to induce an animal model of mucosal inflammation, ${ }^{5}$ and FMLP is one of the bacterial derived factors implicated in the initiation and perpetuation of inflammatory bowel disease.$^{67}$ In addition, because FMLP undergoes an enterohepatic circulation, it might contribute to some of the extraintestinal complications of inflammatory bowel disease including sclerosing cholangitis. ${ }^{48}$ There is also evidence for a proinflammatory role for FMLP in other forms of mucosal inflammation including that associated with Helicobacter pylori. ${ }^{9}$

Although the presence of specific receptors for FMLP on human polymorphs and monocytes is well established, ${ }^{10-12}$ it is unclear whether other cells within the gastrointestinal mucosa, particularly epithelial cells, express FMLP receptors. This is important because FMLP is used experimentally to stimulate phagocytic cells "selectively" in order to examine the influence of their products on epithelial cell function in ion channel and transport studies. ${ }^{13}$ Interpretation of such experiments might be confounded by reports of functional effects of FMLP apparently acting directly on epithelia. ${ }^{14}$ Furthermore, FMLP is thought to be pleiotropic with actions on cells other than phagocytes. ${ }^{12} 1516$ We have therefore used several different experimental approaches to map FMLP receptors within intestinal mucosa.

\section{Materials and methods}

CELL ISOLATION AND CELL LINES

Peripheral blood mononuclear cells were isolated by density centrifugation as described elsewhere ${ }^{17}$ and purification of neutrophils was performed as described in detail by us previously. ${ }^{18}$ For some experiments, peripheral mononuclear cells were depleted of monocytes by plastic adherence, ${ }^{17-19}$ thereby enriching for peripheral blood lymphocytes. There were no contaminant neutrophils with no more than $1 \%$ monocytes in these preparations on flow cytometry and trypan blue staining (viability at least $99 \%$ ).

Isolation of lamina propria mononuclear cells from surgically resected, non-inflamed colonic tissue of patients with colonic cancer was performed as described by us previously. ${ }^{19}$ For some experiments, epithelial cell preparations (at least $80 \%$ on trypan blue staining and flow cytometry) were obtained during the 
lamina propria mononuclear cell isolation process and were studied immediately for the FMLP receptor by flow cytometry. The study was in compliance with the guidelines of the Cork University Human Ethics Committee.

Cell lines were obtained from the European Collection of Animal Cell Cultures (Salisbury, Wilts, UK) and included the gastrointestinal cell lines HT29, SW620, T84, CaCo2, LoVo, WiDr, Colo205, and the myeloid cell line HL60. The oesophageal squamous (OC1 and OC2) and gastroesophageal adenocarcinoma cell lines (OC3) were generated by us. ${ }^{20}$ Primary cultures of non-transformed rabbit ascending colon enterocytes were generously provided by Alda Vidrich (UCLA, Cedars Sinai, Los Angeles, California).

RADIOLIGAND BINDING

Binding of ${ }^{3} \mathrm{H}-\mathrm{FMLP}$ (New England Nuclear, Boston, Massachusetts) to epithelial cells and neutrophils (positive control) was performed as described in detail previously. ${ }^{18}$ Saturation curves using various concentrations of radiolabelled FMLP were generated for each cell type, $2 \times 10^{6}$ incubation tube, at $37^{\circ} \mathrm{C}$ for 20 minutes, and where no binding was detected, the result was confirmed at $22^{\circ} \mathrm{C}$ and $4{ }^{\circ} \mathrm{C}$. Non-specific binding was defined as the amount of radioligand bound in the presence of 1000 -fold excess unlabelled peptide.

FLOW CYTOMETRY USING FMLP-LYS-FITC

Binding of FMLP to epithelial cell lines, whole blood (neutrophils, monocytes, and lymphocytes) and isolated lamina propria lymphocytes was examined by flow cytometry (Coulter, Epics, Elite) using fluorescein (FITC) labelled FMLP-Lys (FMLP-FITC) (Peninsula Laboratories, Belmont, California). Cells $\left(10^{6}\right)$ or whole blood $(100 \mu \mathrm{l})$ were incubated with FMLP-FITC $\left(2 \times 10^{-7} \mathrm{M}\right)$ for 30 minutes at $4^{\circ} \mathrm{C}$, then washed and resuspended and immediately examined by cytometry. To confirm specific, displaceable binding, excess $\left(2 \times 10^{-3} \mathrm{M}\right)$ cold (non-labelled) FMLP was added in parallel conditions. Whole blood was examined by individually gating on the monocyte, granulocyte, and lymphocyte populations.

REVERSE TRANSCRIPTION POLYMERASE CHAIN REACTION DETECTION OF FMLP RECEPTOR MRNA EXPRESSION

RNA was isolated from cells by lysis in guanidine thiocyanate (Sigma Chemical Co., St Louis, Missouri) followed by phenol extraction and ethanol precipitation. cDNA was synthesised using the AMV reverse transcriptase (Promega, Madison, Wisconsin) and random hexanucleotide primers (Boehringer Mannheim $\mathrm{GmbH}$, Mannheim, Germany). Polymerase chain reaction (PCR) was performed on the cDNA using the following sense and antisense primers respectively: GAACTACCCAGAGCAAGACCACAG and GAGGGCGATCAGGAAGACACT to amplify a 456 bp mRNA specific product for the classic FMLP receptor; and GTGGGGCGCCCCAGGCACCA and CTCCTTAATGTCACGCACGATTTC to amplify a $550 \mathrm{bp}$ mRNA specific product for $\beta$ actin (control PCR). PCR primers were designed using the DNAStar Lasergene Primerselect program (DNASTAR, Madison, Wisconsin). Each primer pair was chosen to span introns in their genomic sequences, thus ensuring mRNA specific amplification. Primers were selected which showed no significant homology to any other genes in the EMBL DNA sequence database. Thermal cycling was as follows: denaturation at $96^{\circ} \mathrm{C}$ for 15 seconds; annealing at $55^{\circ} \mathrm{C}$ for 30 seconds; and extension at $72^{\circ} \mathrm{C}$ for three minutes. Thirty five cycles were performed. Primers were used at a final concentration of $0.1 \mu \mathrm{M}$ each, dNTPs at $50 \mu \mathrm{M}$, and $\mathrm{MgCl}_{2}$ at $1.5 \mathrm{mM} ; 1.0 \mathrm{U}$ of Taq DNA polymerase (Promega) was used per $50 \mu$ reaction. PCR products were analysed by electrophoresis through $2 \%$ agarose gels and viewed under ultraviolet light following ethidium bromide staining. Hae III digested $\Phi$ X174 DNA size markers were used (Promega). PCR product specificities were confirmed by restriction mapping.

IN SITU TISSUE STAINING WITH FMLP-LYS-FITC Resected colonic tissue from human and rabbit was immediately rinsed in cold saline, divided, and embedded in OCT at $-25^{\circ} \mathrm{C}$. Transmural cryostat sections were cut at $10 \mu \mathrm{m}$, mounted on poly-l-lysine coated glass slides and stored at $-75^{\circ} \mathrm{C}$ until probed for FMLP binding with fluorescein labelled peptide (FMLP-LysFITC). Slides were incubated with FMLPLys-FITC diluted in phosphate buffered saline (pH 7.2) to $10^{-6}-10^{-9} \mathrm{M}$, with an optimum concentration of $10^{-7} \mathrm{M}$, ultimately used for binding experiments. Control experiments were performed in the absence of any FMLP probe and using excess $\left(10^{-3} \mathrm{M}\right)$ cold (nonFITC labelled) FMLP (Sigma) to determine non-specific/displaceable binding. The incubations were performed at $4^{\circ} \mathrm{C}$ in the dark overnight to allow equilibration of the ligands with the tissue binding sites, in a moist enviroment. This time period minimised non-specific background fluorescence. The incubation period was terminated by rapid rinses in cold phosphate buffered saline $(4 \times 30$ seconds each), and the slide mounted colon sections were allowed to dry in the dark. The sections were examined using a $100 \mathrm{~W}$ mercury burner and the appropriate dichroic filter combination excitation/emission of the derivatised FMLP fluoroprobe; $485 / 520 \mathrm{~nm}$ filters for fluorescein using a Nikon Fluophot photomicroscope. Photomicrographs were made using 400 ASA colour film (Kodak Gold). Objectives of 10X and $20 \times$ were used for examination of sections.

\section{Results}

RADIOLIGAND BINDING

Control studies with polymorphonuclear neutrophils revealed saturable binding with ${ }^{3} \mathrm{H}-$ FMLP with a $\mathrm{Kd}$ of $18.9 \mathrm{nM}$ and approximately 19500 receptors per cell which is within the range previously published by us and by others. ${ }^{10} 18$ In contrast, neither rabbit ascending colon (RAS) nor HT29 colonocytes 

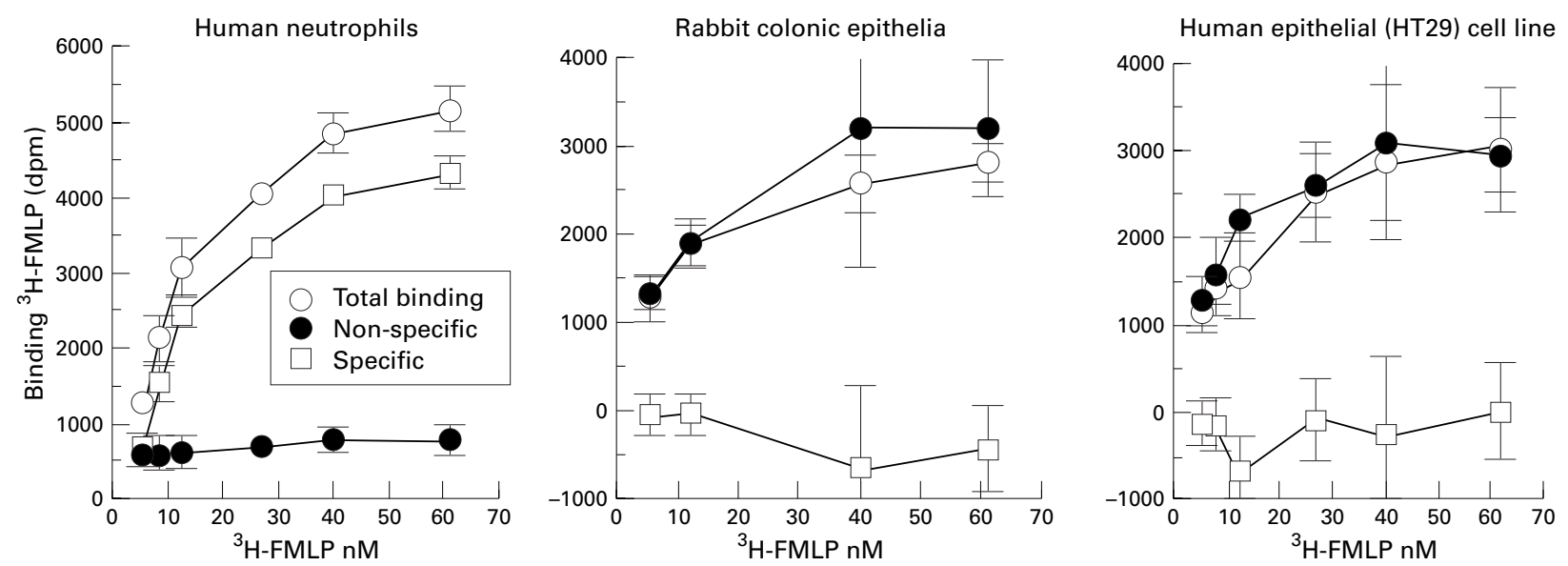

Figure 1 Radioligand binding with ${ }^{3}$ H-FMLP, showing that human neutrophils but not primary untransformed colonocytes or human colon (HT29) carcinoma epithelial cells express specific binding sites.

A

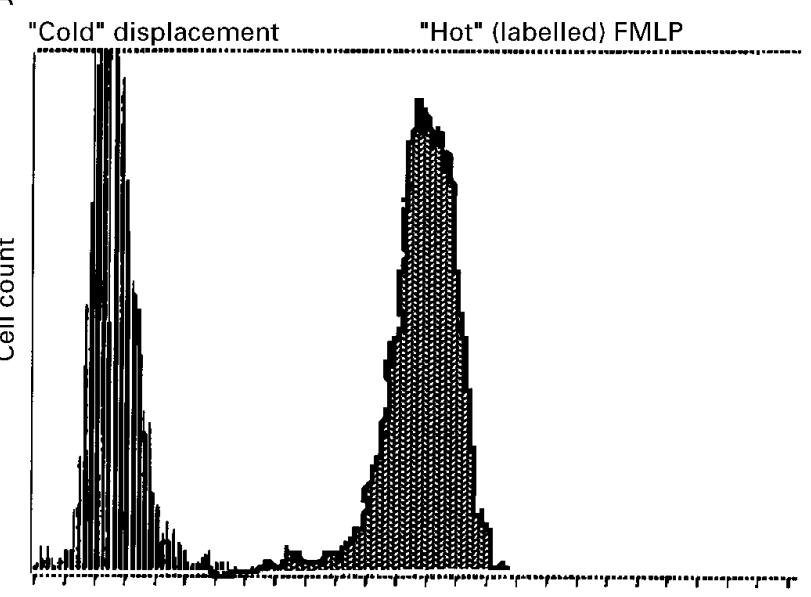

Fluorescence $\longrightarrow$

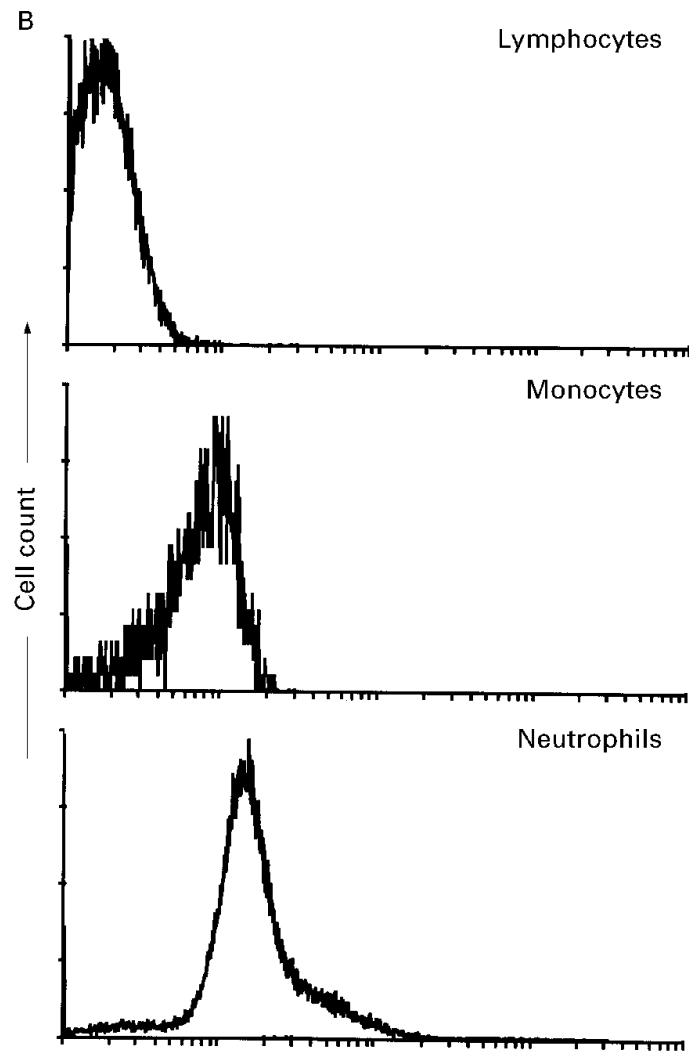

Fluorescence

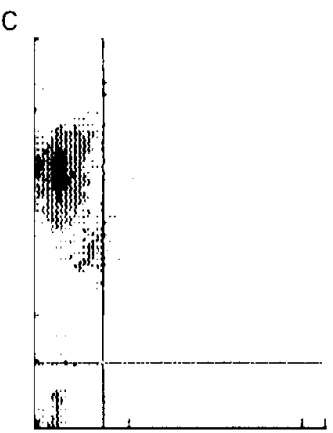

Neutrophils

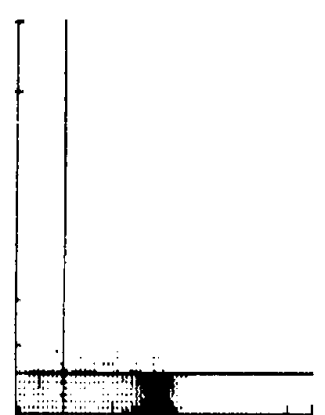

Neutrophils

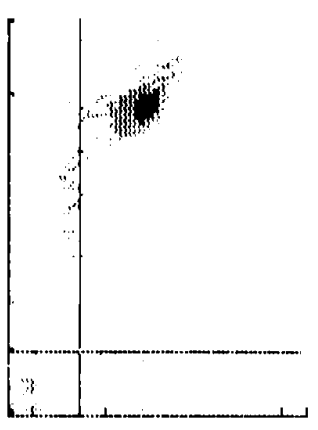

Neutrophils

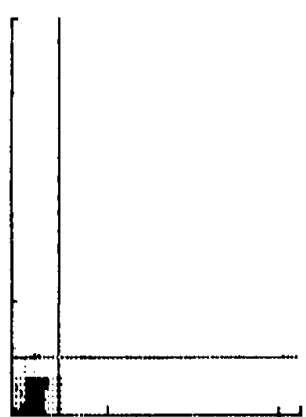

Lymphocytes

Figure 2 (A) Use of flow cytometry to show specific, displaceable binding of FMLP-Lys-FITC to purified neutrophils. (B) Flow cytometry of whole blood using FMLP-Lys-FITC showing that neutrophils and monocytes but not lymphocytes bind FMLP (representative of five similar experiments). (C) Flow cytometry using purified neutrophils and lymphocytes stained with FMLP-Lys-FITC and phycoerythrin conjugated anti-CR3 (complement component 3 receptor; CD11). All neutrophils and none of the lymphocytes express both receptors. 


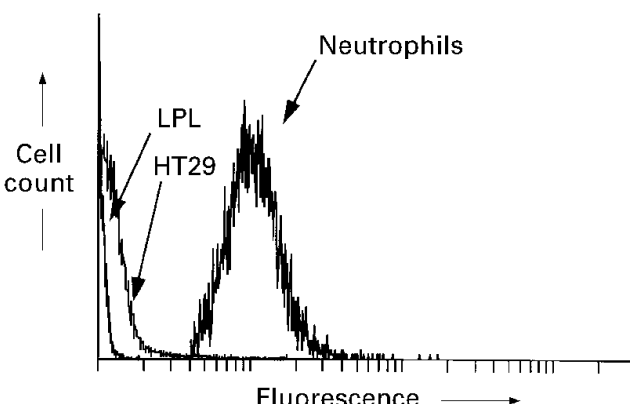

Figure 3 Flow cytometry showing that in contrast to neutrophils, significant binding of FMLP to intestinal lamina propria lymphocytes ( $L P L ; n=5$ different experiments) or epithelial cells is not evident (similar negative results were obtained with the other epithelial cell lines).
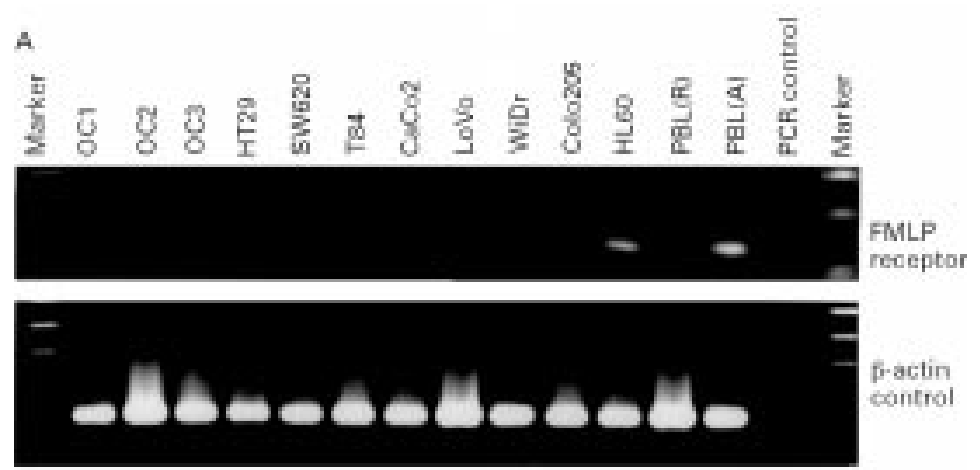

B
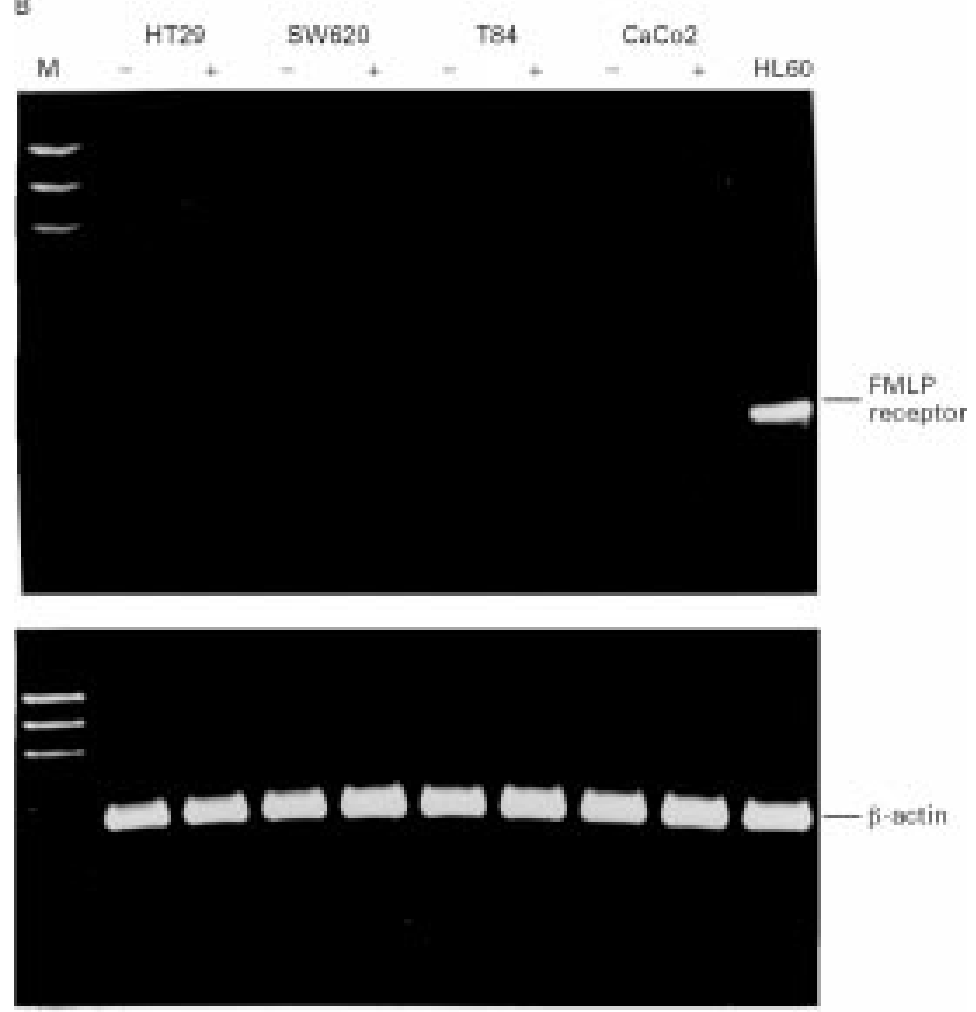

Figure 4 (A) Absence of FMLP receptor $m R N A$ expression in 10 gastrointestinal epithelial cell lines. Resting and PMA/ionomycin activated peripheral blood mononuclear cells $(P B L(R)$ and $P B L(A)$, respectively) containing unfractionated monocytes and lymphocytes, were used as negative and positive controls respectively. (B) Absence of FMLP receptor expression in cytokine stimulated colonic epithelial cell lines. FMLP receptor specific RT-PCR was performed on HT29, SW620, T84 and CaCo2 cells following incubation in absence ( $(-)$ or presence ( + ) of IFN- $\gamma, T N F-a$, and IL-1. HL60 cells were used as a positive control for FMLP receptor expression. exhibited any significant specific binding, but did exhibit notable non-specific binding (fig 1).

FLOW CYTOMETRY

Specific displaceable binding of FMLP-LysFITC to neutrophils was confirmed by flow cytometry and illustrated graphically (fig 2A). Cytometry on whole blood confirmed that granulocytes and monocytes, but not lymphocytes, were positive for FMLP binding (fig 2B). Confirmation that the technique could reliably distinguish FMLP receptor bearing cells from non-receptor bearing cells was obtained using purified neutrophils and peripheral lymphocytes, and evidence that all (or virtually all) neutrophils express the FMLP receptor was found with secondary costaining for the CR3 receptor (CD11). As expected, all neutrophils and none of the lymphocytes were positive for both FMLP receptor and CD11 (fig 2C).

Isolated lamina propria lymphocytes (LPL) from five separate colonic specimens had no detectable FMLP staining and none of the epithelial cell lines exhibited specific staining (fig 3 ). In addition, there was no detectable FMLP staining of freshly isolated epithelial cell preparations (at least $80 \%$ epithelial, at least $90 \%$ viable, trypan blue exclusion) obtained from four colonic specimens (two of which were from patients with ulcerative colitis) and one ileal resected specimen.

FMLP RECEPTOR MRNA EXPRESSION

Reverse transcription (RT)-PCR results showed that none of the colonic or gastrooesophageal epithelial cell lines expressed mRNA for the FMLP receptor (fig $4 \mathrm{~A}$ ). The FMLP receptor RT-PCR assay was controlled by equalisation of input RNA for each cell line. Comparable amplification efficiencies were achieved in all RNA samples as evidenced by the uniformity of control $\beta$ actin RT-PCR product yielded. Equivalent PCR product band intensities suggest that peripheral blood mononuclear cells activated with PMA/ ionomycin express a level of FMLP receptor mRNA that is qualitatively similar to that expressed in the HL60 positive control myeloid cell line.

To determine whether a message for the FMLP receptor might be induced in epithelial cells in the presence of proinflammatory cytokines, epithelial cell lines were incubated for 12 hours in the presence and absence of interferon $\gamma$ (IFN- $\gamma$ ), tumour necrosis factor $\alpha$ $(\mathrm{TNF}-\alpha)$, and interleukin 1 (IL-1) at $10 \mathrm{ng} / \mathrm{ml}$ for each. Under these conditions, RT-PCR for the receptor message remained undetectable (fig 4B).

FMLP BINDING IN SITU

To map the binding sites of FMLP in situ and to rule out the possibility of binding to epithelial cells through other peptide receptors, direct staining of unfixed human and rabbit colonic tissue was performed with FITC labelled FMLP-Lys. The results show that the binding is subepithelial, and seems to represent cellular binding, possibly to phagocytes within the 


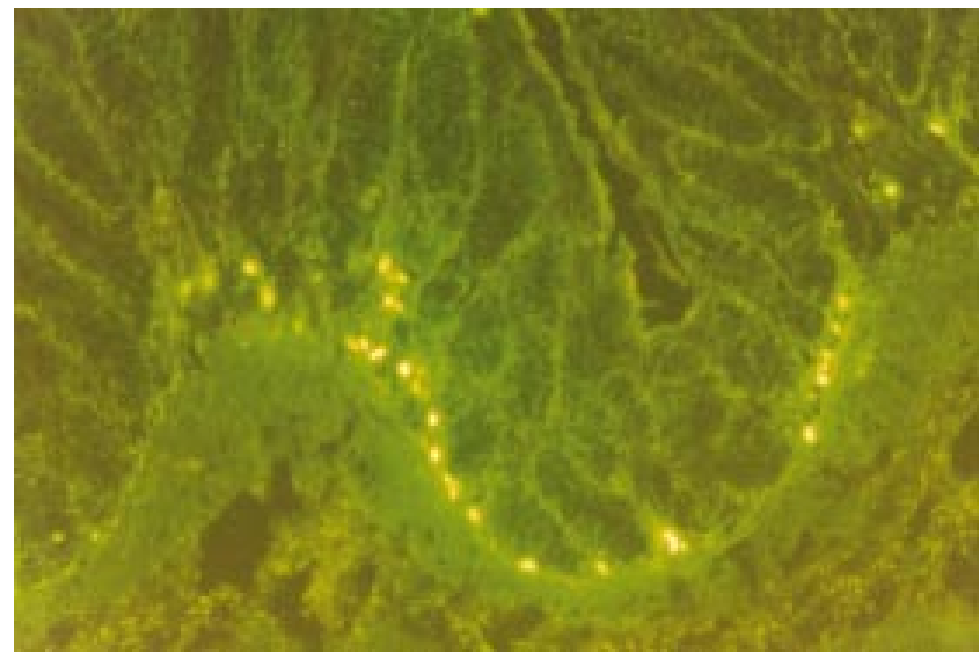

Figure 5 Direct staining with FMLP-Lys-FITC of an unfixed, cyrostat section of colonic mucosa showing subepithelial location of binding sites.

lamina propria although there may be other receptor bearing cells such as mast cells, dendritic cells, or enterochromaffin cells (fig 5). Due to the unfixed nature of the specimen, rigorous cellular detail is not possible with this technique. Proximal and distal colon did not differ noticeably with respect to binding of FMLP.

\section{Discussion}

The most important objective of the study was to determine whether gastrointestinal epithelia express receptors for FMLP. The results which were generated with four different techniques including radioligand binding, flow cytometry, RT-PCR, and in situ staining, show no evidence for receptors for FMLP on enterocytes. The data confirm that the binding sites for FMLP in the gastrointestinal mucosa are subepithelial and probably exclusive to polymorphs and monocytic phagocytes. Although mast cells were not specifically examined in this study, it has previously been shown that human intestinal mast cells, unlike peripheral blood basophils, do not respond to FMLP. ${ }^{21}$ Our radioligand binding results for neutrophils are similar to those reported by others and by us previously, ${ }^{10} 1118$ and show no significant binding to either a primary culture of rabbit epithelial cells or transformed human colonocytes.

The use of flow cytometry with fluorescence labelled ligand provided additional confirmation of the results and further evidence to exclude the possibility that FMLP may be binding to a small subset of epithelial cells. In contrast to radioligand binding studies, which generate data for an overall population of cells, flow cytometry offers the advantage of counting individual cells and has been used by others to examine FMLP receptors. ${ }^{22}$ The possibility that receptor expression might be present in low numbers on some cell types below the detection sensitivity for radiolabelled or fluorescence labelled ligand binding assays, seems unlikely because epithelial and control cell lines were probed for receptor mRNA by RT-PCR, and receptor message was not detected in any of the 10 epithelial cell lines tested. Finally, in situ staining with fluorescence labelled FMLP ruled out the possibility of epithelial binding by FMLP via receptors for structurally similar peptides such as the tachykinins, ${ }^{23}$ and provided conclusive confirmation that the mucosal distribution of binding is subepithelial.

FMLP has been reported to have multiple effects on gastrointestinal function which may be interrelated and include increased mucosal and microvascular permeability, increased smooth muscle tone, and acute inflammation. ${ }^{24-26}$ The effect on mucosal permeability seems to be pivotal since it has the potential for creating an amplification effect or vicious cycle which may be particularly relevant in mucosal inflammation. ${ }^{26}$ FMLP mediated enhanced mucosal permeability associated with a proinflammatory and chemotactic microenvironment would lead to further increases in permeability and promote greater ingress of FMLP with other luminal factors, thereby amplifying the inflammatory sequence.

It is generally assumed that the effects of FMLP on gastrointestinal function are mediated primarily by granulocytes, notwithstanding the pleiotropic nature of FMLP and reported direct action on epithelial cell function. ${ }^{12}{ }^{14}$ The evidence for this is based largely on granulocyte depletion experiments. ${ }^{26}$ Our results are also consistent with this. Since receptor mediated effects of FMLP are subepithelial, any effects on permeability must be indirect.

Studies with epithelial cell monolayers have shown that access to subepithelial receptor bearing phagocytes by FMLP is via the paracellular pathway. ${ }^{27}$ The chemotactic gradient of FMLP induces transmigration of subepithelial granulocytes across the epithelium through intercellular tight junctions. It seems that a reversible loosening of tight junctions by the transepithelial migration of granulocytes may be the mechanism of FMLP mediated increased mucosal permeability. ${ }^{28} 29$

Counter-regulatory measures preventing unrestricted access and FMLP mediated enhanced mucosal permeability undoubtedly exist in vivo. These include the presence of mucosal peptidases capable of degrading bacterial FMLP and other chemotactic peptides. ${ }^{30}$ In addition, the intestinal epithelium has evolved the ability to express major histocompatibility complex (MHC) class I like molecules that preferentially bind to and present bacterial derived $N$-formylated peptides to the immune system. ${ }^{31} 32$ However, this is not a true receptor-ligand interaction and would, therefore, not be detectable by conventional radioligand binding assays. In addition, it involves such a small number of surface molecules that it would not be detected by flow cytometry.

In conclusion, specific receptors for FMLP are confined to the subepithelial layer of the colonic mucosa. They are not present on epithelial cells or lamina propria lymphocytes. The receptor bearing cells may be phagocytes, although the possibility of other receptor bearing cells such as mast cells, dendritic cells, or even enterochromaffin cells was not excluded. 
The results support the interpretation of earlier granulocyte depletion experiments in suggesting that the actions of FMLP on gastrointestinal function are indirect and mediated by phagocytes or other lamina propria cells.

The authors are funded by the Health Research Board of Ireland. This work was presented in part at the AGA/DDW annual meeting, San Franscisco, May 1996, and published in abstract form (Gastroenterology 1996;110:A856).

1 Chadwick VS, Mellor DM, Myers DB, et al. Production of peptides inducing chemotaxis and lysosomal enzyme release in human neutrophils by intestinal bacteria in vitro and in vivo. Scand 7 Gastroenterol 1988;23:121-8.

2 Marasco W, Phan SH, Krutzsch H, et al. Purification and identification of formyl-methionyl-leucyl-phenylalanine as the major peptide neutrophil chemotactic factor produced the major peptide neutrophil chemotactic factor prod

3 Hobson CH, Roberts EC, Mellor DM, et al. Radioimmunoassay for formyl-methionyl-leucyl-phenylalanine (FMLP): I. Development and application to assessment of chemotactic peptide production by enteric bacteria. $\mathcal{F}$ Gas troenterol Hepatol 1990;5:32-7.

4 Roberts EC, Hobson CH, Anderson RP, et al. Radioimmunoassay for formyl-methionyl-leucyl-phenylalanine (FMLP): II. Demonstration of an enterohepatic circulation of immunoreactive bacterial chemotactic peptides in man f Gastroenterol Hepatol 1990;5:38-43.

5 Chester JF, Ross JS, Malt RA, et al. Acute colitis produced by chemotactic peptides in rats and mice. Am $\mathcal{f}$ Pathol 1985;121:284-90.

6 Nast CC, Leduc LE. Chemotactic peptides: mechanisms, functions, and possible roles in inflammatory bowel disease. Dig Dis Sci 1988;33:50S-57S.

7 Sartor RB. Role of intestinal microflora in initiation and perpetuation of inflammatory bowel disease. Can $\mathcal{f}$ Gastroperpetuation of inflam

8 Ferry DM, Butt TJ, Broom MF, et al. Bacterial chemotactic oligopeptides and the intestinal mucosal barrier. Gastroenterology 1989;97:61-7.

9 Mooney C, Keenan J, Munster D, et al. Neutrophil activation by Helicobacter pylori. Gut 1991;32:853-7.

10 Sklar A, Jesaitis AJ, Painter RG. The neutrophil N-formyl peptide receptor: dynamics of ligand-receptor interactions and their relationship to cellular responses. Contemp Top Immunobiol 1984;14:29-82.

11 Koo C, Lefkowitz RJ, Snyderman R. The oligopeptide chemotactic factor receptor on human polymorphonuclear leukocyte membranes exists in two affinity states. Biochen Biophys Res Commun 1982;106:442-9.

12 Murphy PM. The molecular biology of leukocyte chemoattractant receptors. Annu Rev Immunol 1994;12:593-633.

13 Stack WA, Keely SJ, O'Donoghue DP, et al. Immune regulation of human colonic electrolyte transport in vivo. Gut 1995;36:395-400.

14 LeDuc LE, Brown L, Vidrich A. Bradykinin and FMLP stimulate prostanoid production by adult rabbit colonocytes in culture. Am f Physiol 1994;267:G778-85.
15 Dunkel CG, Saffitz JE, Evers AS, fMet-Leu-Phe receptor expression by an interstitial cell in rabbit right atrium following left ventricular myocardial infarction. Circ Res 1989;65:215-23.

16 Ballesteros LM, Delgado NM, Rosado A, et al. Binding of chemotactic peptide to the outer surface and to whole human spermatozoa with different affinity states. Gamete Res 1988;20:233-9.

17 Boyum A. Isolation of leukocytes. Scand f Clin Lab Invest 1968;21 (suppl 97):9-109.

18 Anton PA, Targan SR, Shanahan F. Increased receptors for and response to the proinflammatory bacterial peptide FMLP in Crohn's disease. Gastroenterology 1989;97:20-8.

19 Shanahan F, Brogan M, Targan S. Human mucosal cytotoxic effector cells. Gastroenterology 1987;92:1951-7.

20 Collins JK, O'Mahony A, O'Brien F, et al. Evaluation of newly established cell lines as models to study growth, invasion, and metastatic spread in oesophageal cancer. Fibrinolysis 1992;6(suppl 4):83-8.

21 Nolte H, Spjeldnaes N, Kruse A, et al. Histamine release from gut mast cells from patients with inflammatory bowel diseases. Gut 1990;31:791-4.

22 Allen CA, Broom MF, Chadwick VS. Flow cytometry analysis of the expression of neutrophil FMLP receptors. 7 Immunol Methods 1992;149:159-64.

23 Marasco WA, Showell HJ, Becker EL. Substance P binds to the formylpeptide chemotaxis receptor on the rabbit neutrophil. Biochem Biophys Res Commun 1981;99:1065-

24 Magnusson KE, Dahlgren C, Sjolander A. Effect of $\mathrm{N}$-formylated-methionyl-leucyl-phenylalanine on gut permeability. Inflammation 1985;9:365-73.

25 Granger DN, Zimmerman BJ, Sekizuka E, et al. Intestinal microvascular exchange in the rat during luminal perfusion with formyl-methionyl-leucyl-phenylalanine. Gastroenterology 1988;94:673-81.

26 Von Ritter C, Sekizuka E, Grisham MB, et al. The chemotactic peptide N-formyl-methionyl-leucyl-phenylalanine increases mucosal permeability in the distal ileum of the rat. Gastroenterology 1988;95:651-6.

27 Riehl TE, Stenson WF. Mechanisms of transit of lipid mediators of inflammation and bacterial peptides across intestinal epithelia. Am f Physiol 1994;267:G687-95.

28 Nash S, Stafford J, Madara JL. Effects of polymorphonuclear leukocyte transmigration on the barrier function of cultured intestinal epithelial monolayers. 7 Clin Invest 1987;80:1104-13.

29 Madara JL. Loosening tight junctions. Lessons from the intestine. 7 Clin Invest 1989;83:1089-94.

30 Chadwick VS, Schlup MM, Cooper BT, et al. Enzymes degrading bacterial chemotactic F-met peptides in human ileal and colonic mucosa. F Gastroenterol Hepatol 1990;5: 375-81.

31 Vyas JM, Rodgers JR, Rich RR. H-2M3 ${ }^{a}$ violates the paradigm for major histocompatibility complex class I peptide binding. F Exp Med 1995;181:1817-25.

32 Melián A, Beckman EM, Porcelli SA, et al. Antigen presentation by $\mathrm{CD} 1$ and MHC-encoded class I-like molecules. Curr Opin Immunol 1996;8:82-8. 